\title{
SECURING EPIDURAL CATHETERS
}

\author{
BRIAN L. DUFFY
}

\begin{abstract}
Conventional dressings do not al ways prevent epidural catheter movement into or out of the epidural space. Lack of transparency also prevents observation of the catheter and the puncturc sitc.

The "Op-site" surgical dressing is an adherent membrane which has prevented epidural catheter migration in 200 obstetrical patients. The transparent dressing was left uncovered in 100 of these patients so that the catheter could be readily seen and the presence of blood within the catheter could be detected at any time,
\end{abstract}

KEY WORDS: ANAESTHETIC TECHNIQUES, epidural; EquiPMENT, epidural catheters.

CLINICAL INSTRUCTORS and text-books of anaesthesia place considerable emphasis on safe, accurate location of the epidural space and careful, correct placment of the epidural catheter. However very little advice is given about secure fixation of the successfully placed catheter. Either no mention is made or a simple recommendation is given to cover with gauze swabs and hold in position by waterproof tape. It is only necessary to watch colleagues to appreciate the infinite and varied interpretations of this advice. Bulky dressings permit catheter movement and conventional tape is opaque, preventing observation of the catheter site. In this paper I describe the use of a sterile dressing which firmly fixes the catheter in place and, being transparent, allows staff to observe the catheter site continuously.

\section{Materials and Methods}

The "Op-site" dressing is thin and transparent, elastic, effectively adherent and has low allergenic potential, thus minimizing the risk of skin sensitization. The membrane is permeable to moisture yapour and air so that the skin remains ventilated. However, it excludes water, bacteria and dirt, thus reducing the chance of external infection. After successful cannulation of the epidural space by the required length of epidural catheter a thin film of "Rikospray" is applied to the skin of the back. This permits a loop of catheter to adhere to the skin. The looped

Brian L. Duffy, M.B., B.S., D.O.B.S.T., R.C.O.G., F.F.A.R.C.S., Department of Anaesthesia, The Queen Elizabeth Hospital, Woodville, 5011, South Australia, Australia. catheter and puncture site are then covered with an "Op-site" wound dressing $(10 \mathrm{~cm} \times 14 \mathrm{~cm})$. This thin elastic membrane may itself be covered with gauze swabs and plaster or left uncovered as in Figure 1. The green edges are cut off or may be left and covered with "Sleek" waterproof dressing to prevent the edges from lifting. The rest of the catheter is taped across the back and over the right shoulder with transparent tape. The patient may now move about freely as desired because the dressing is firmly adherent to the catheter and both are bound to the skin.

\section{RESULTS}

The "Op-site" dressing has been used in over 200 obstetrical patients. No case of untoward movement of the catheter into or out of the epidural space has occurred. In two patients blood collecting in the catheter between top-up injections was detected and flushed with saline

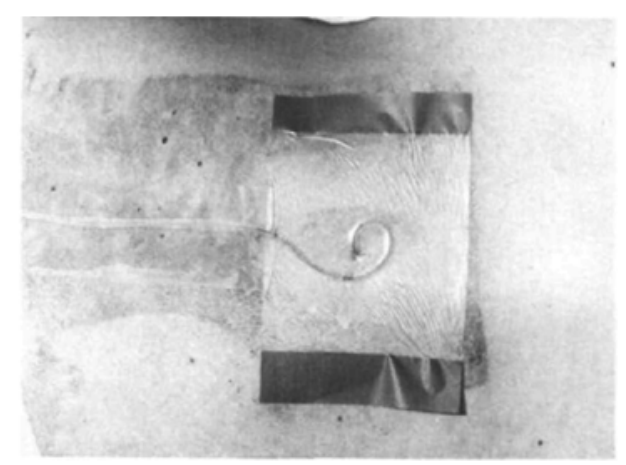

Figure 1 Epidural catheter held in place by transparent dressing.

Can. Anaesth. Soc. J. vol. 29, no. 6, November 1982 
before blockage occurred. There was no kinking of the catheter at the skin edge. Haemostasis of the skin puncture site is necessary before application of the dressing because blood cannot penetrate the membrane. Continued bleeding may obscure visibility. Although the membrane is moisture vapour permeable, in hot conditions a small pool of unevaporated sweat has collected beneath the membrane on a few occasions. No harm appears to have come from this. The dressing has remained in place for up to 48 hours and has performed very satisfactorily.

\section{Discussion}

Accidental displacement from the epidural space of a correctly positioned catheter may be more than just a nuisance for the anaesthetist. Difficulties may be encountered in replacing a catheter. The advance of labour may mean that a repeat attempt will be made in a patient having frequent contractions so that perforation of blood vessel or dura might occur. Loss of a functioning epidural catheter may pose risks for cardiac or toxaemic patients if there is delay in instituting another block.

A catheter which migrates further into the epidural space may give rise to unilateral or partial blocks. Penetration into a blood vessel may result in subsequent accidental intravenous injection of local anaesthetic ${ }^{2}$ or, at the very least, a totally blocked catheter. Finally total spinal anaesthesia following previous uncomplicated top-ups ${ }^{3}$ may occur as the result of inward catheter migration.

The adherent Op-site dressing does effectively prevent catheter movement. Originally, the small intravenous site dressing $(6 \mathrm{~cm} \times 8.5 \mathrm{~cm})$ was used ${ }^{4}$ but it had to be covered with gauze swabs and adhesive plaster. The larger wound dressing does not need to be covered. Aspiration before incremental injections is routine in our unit, so it is a great advantage to be able to see as much of the catheter as possible. The presence of blood in the catheter between injections can be seen and dealt with before intra-luminal obstruction occurs.

One of the reasons given for the use of bulky gauze dressings is to prevent catheter kinking and, in fact, a perspex shield was described to overcome this alleged problem. ${ }^{5}$ Modern catheters do not kink at the skin edge. Any kinking takes place between the vertebral spines ${ }^{6}$ or, more commonly, within the supraspinous ligament. ${ }^{7}$ Certainly no catheter kinking has been observed following the use of the uncovered dressings.

The "Op-site" dressings are used for many days or weeks on surgical wounds, so they would be expected to be suitable for long-term epidural catheterization, for instance thoracic epidural blocks in Intensive Care Units.

In conclusion, the "Op-site" dressing is a sterile adherent dressing, easily applied, which effectively prevents catheter movement into or out of the epidural space. Being transparent, the dressing permits continuous observation of the catheter site so that entry of blood into the catheter is readily detected. Catheter adjustment can be undertaken after simply peeling off the dressing. It has been found to have solved completely the problem of the migrating catheter as well as giving ready visual and physical access to the site. I believe it is a valuable adjunct to the safe management of continuous lumbar epidural analgesia.

\section{REFERENCES}

1. Crawford, J.S. Principles and Practice of Obstetric Anaesthesia. 4th Edition Oxford: Blackwell Scientific Publications: 150-242 (1978).

2. RYAN, D.W. Accidental intravenous injection of bupivacaine: a complication of obstetric epidural anaesthesia. Brit. J. of Anaes. 45: 907-908 (1973).

3. Philip, J.H. \& BRown, W.U. Total spinal anaesthesia late in the course of obstetric bupivacaine epidural block. Anesthesiology 44: 340341 (1976).

4. DuFFY B.L. Epidural catheter fixation. Anacst. and Inten. Care 9: 292 (1981)

5. Climie, C.R. Shield for epidural catheters. Anaesthesia 15: 331 (1960).

6. KaUfMaN, R.D. \& REYNOLDS, R.C. Occlusion of an epidural catheter secondary to osteoarthritis. Anesthesiology 44: 253-255 (1976).

7. Doughty, A. The relief of pain in labour. In: Churchill-Davidson, H.C. ed. A Practice of Anaesthesia. 4th ed. London: Lloyd-Luke (Medical Books) Lid: 1302-1354 (1978).

\section{RÉSUME}

Les pansements conventionnels n'empêchent pas toujours les cathéters périduraux de sortir de l'espace épidural. L'absence de transparence ne permet pas d'observer le cathéter et l'endroit de la ponction.

Le pansement chirurgical "OP-SITE" consiste en une membrane adhérante qui a empêché la migration du cathéter péridural dans 200 cas obstétricaux. Chez cent patientes on n'a pas recouvert le pansement transparent de sorte que le cathéter était facilement visible et que la présence de sang pouvait être détectée en tout temps. 